\title{
Free vibration of circular annular plate with different boundary conditions
}

\author{
Yash Jaiman', Baij Singh ${ }^{2}$ \\ ${ }^{1}$ Bennett University, Greater Noida, Uttar Pradesh, India \\ ${ }^{2}$ Indian Institute of Technology (ISM), Dhanbad, India \\ ${ }^{1}$ Corresponding author \\ E-mail: ${ }^{1}$ yash.jaiman24@outlook.com, ${ }^{2}$ singhbaij03@gmail.com
}

Received 23 October 2019; accepted 4 November 2019

DOI https://doi.org/10.21595/vp.2019.21116

Check for updates

Copyright (C) 2019 Yash Jaiman, et al. This is an open access article distributed under the Creative Commons Attribution License, which permits unrestricted use, distribution, and reproduction in any medium, provided the original work is properly cited.

\begin{abstract}
This paper deals with the numerical simulation of free vibration analysis of a thin circular annular plate for various boundary conditions at the outer edge and inner edge. Classical plate theory is used to derive the governing differential equation for the transverse deflection of the thin isotropic plate. The finite element method is used to evaluate the first six natural frequencies and mode shapes of the thin uniform circular annular plate with radius ratios $\left(r_{1} / r_{2}\right)$ for different boundary conditions. These natural frequencies results are compared with those available in the literature. The results are verified with classical plate theory with our Abaqus results and checked with the previous research literature on the topic.
\end{abstract}

Keywords: circular annular plate, free vibration, numerical simulation.

\section{Introduction}

Plates are widely used as a structural element and have vast practical applications in many engineering fields such as aerospace, mechanical, civil, nuclear, electronic, automotive, marine and heavy machinery, etc. Various researchers have analyzed the free vibration behavior of circular annular plates of different shapes, sizes, thickness for different boundary conditions. Leissa [1] used the Ritz method to estimate the natural frequencies of the isotropic plate for different boundary conditions. Kim and Dickinson [2] used the Rayleigh-Ritz approximation method for free vibration of a thin plate to extract natural frequencies. Rajalingham et al. [3] used a Rayleigh-Ritz method to analyze the plate characteristics parameter as shape functions and continued his work to formulate a variational reduction expression to analyze frequencies and mode shapes. Liew et al. [4] used the polynomials-Ritz method for the vibration of circular plates by using three-dimensional elasticity solutions. Zhou et al. [5] used the Chebyshev-Ritz method for three-dimensional vibration and mode shapes of the circular plate. Lim et al. [6] used the state-space method to analyze transverse vibration and mode of a thick circular plate. Zhou et al. [7] used the Hamiltonian principle to solve governing equations for free vibration analysis by using the variational principle of mixed energy method. Kumar et al. [8] use a dynamic stiffness method to extract the natural frequency and mode shapes of a thin plate. Piyush et al. [9] used the Rayleigh-Ritz method to compute the natural frequencies of the thin plate.

\section{Basic formulation}

Consider a homogeneous, isotropic circular annular plate in cylindrical coordinates $(r, \theta, z)$ with uniform thickness $h$ as shown in Fig. 1 .

Classical plate theory is used to derive the governing differential equation for transverse vibration in the polar coordinate system is defined as:

$D \nabla^{4} W(r, \theta, t)+\rho h w(r, \theta)=0, \quad \nabla^{4}=\nabla^{2} \nabla^{2}$, 
where Laplacian operator: $\nabla^{2}=\frac{\partial^{2}}{\partial r^{2}}+\frac{1}{r} \frac{\partial}{\partial r}+\frac{1}{r^{2}} \frac{\partial^{2}}{\partial \theta^{2}}, \rho$ is the mass density, $D=E h^{3} /\left[12\left(1-v^{2}\right)\right]$ is the flexural rigidity and $v$ is Poisson's ratio.

Transverse deflection of natural vibrations for thin circular plate is assumed to be:

$W(r, \theta, t)=w(r, \theta) e^{i \omega t}$,

where $\omega$ is the natural frequency and $w(r, \theta)$ is natural mode.

Substituting Eqs. (2) in (1), we get:

$\nabla^{4} W-\gamma^{4} W=0, \quad$ or $\left(\nabla^{2}+\gamma^{2}\right)\left(\nabla^{2}+\gamma^{2}\right) W=0$,

where:

$\gamma^{4}=\frac{\rho h \omega^{2}}{D}$

The general finite element equation for the transverse deflection of thin plate is given by:

$$
[M]\{\ddot{q}\}+[K]\{q\}=0,
$$

where $[M]$ is the mass matrix, $[K]$ is stiffness matrix, $\{\ddot{q}\}$ is the nodal acceleration vector, and $\{q\}$ is nodal displacement vector.

The non-dimension natural frequency parameter $\varpi$ are calculated as:

$\varpi=2 \pi \omega[\sqrt{\rho h / D}] r_{1}^{2}$,

where $\omega$ is the natural frequency in $\mathrm{Hz}$.

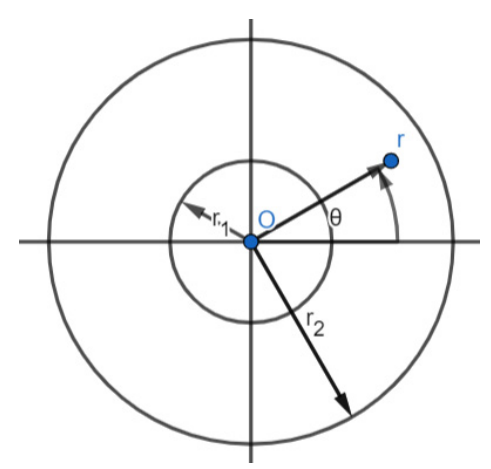

Fig. 1. Schematic diagram and coordinate system of annular circular plate

\section{Results and discussions}

In this section, the first six non-dimensional natural frequencies and mode shapes of the circular annular plate are estimated by using the finite element method. Here, we calculated different eigenvalues for different boundary conditions with different radii ratio $\left(r_{1} / r_{2}\right)$. Different combinations of boundary conditions are applied to compute the natural frequencies and mode shapes of the circular annular plate. 2820 elements and 5922 nodes are used to estimate the natural frequencies and mode shape function of thin circular annular plates after convergence study. The present natural frequencies results are compared with those available in the literature.

Tables 1-4 shows that the first six non-dimensional natural frequencies values for the circular annular plate. These present results are nearly the same as Leissa [1] and Zhou [8] under different 
boundary conditions.
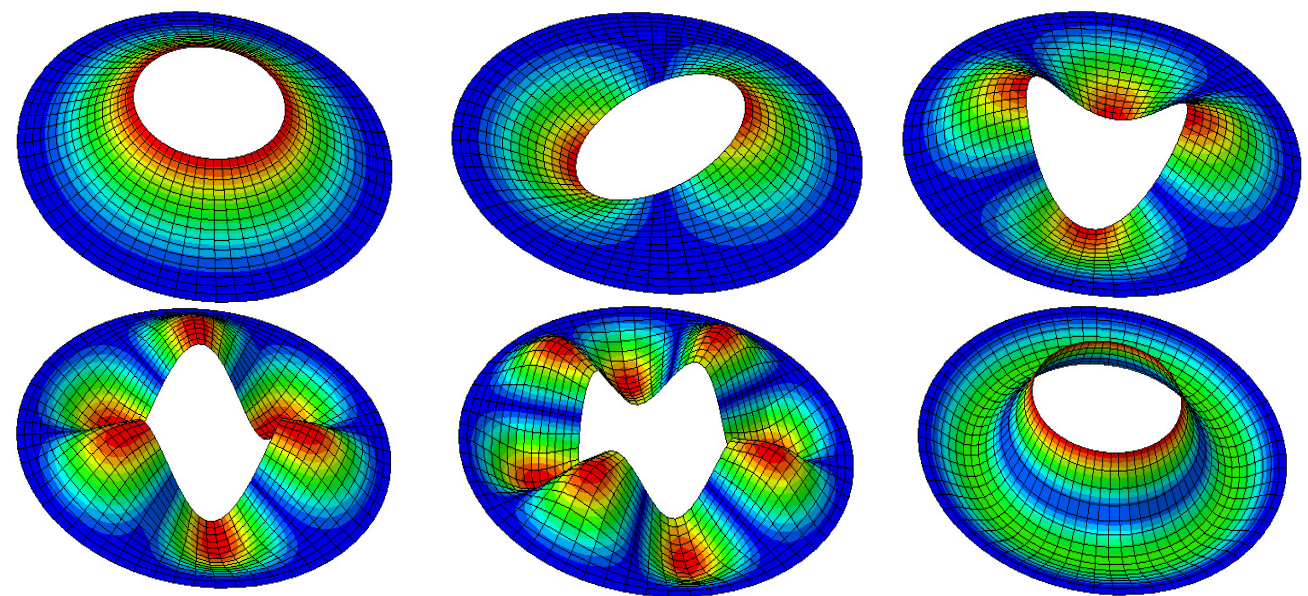

Fig. 2. Natural modes of a clamped annular plate with a free inner boundary, $r_{1} / r_{2}=0.4$

Table 5-7 presents the effect of the radii ratio on the non-dimensional frequency parameter of thin plates. It is observed from these tables that as the radii ratio increases non-dimensional frequency parameter increases.

Table 1. Comparison of the non-dimensional natural frequency parameter with Leissa [1] and Zhou [8] for clamped outer and free inner boundary $\left(v=1 / 3, r_{1} / r_{2}=0.4\right)$

\begin{tabular}{|c|c|c|c|c|c|c|}
\hline \multirow{2}{*}{ Results } & \multicolumn{7}{|c|}{ Mode number } \\
\cline { 2 - 7 } & 1 & 2 & 3 & 4 & 5 & 6 \\
\hline Leissa [1] & 13.54 & 19.80 & 31.34 & - & - & - \\
\hline Zhou [8] & 13.500 & 19.389 & 31.338 & 46.855 & 65.984 & 66.924 \\
\hline Present & 12.871 & 18.497 & 29.901 & 44.70 & 62.982 & 63.935 \\
\hline
\end{tabular}

Table 2. Comparison of the non-dimensional natural frequency parameter with Leissa [1] and Zhou [8] for free outer and clamped inner boundary $\left(v=1 / 3, r_{1} / r_{2}=0.4\right)$

\begin{tabular}{|c|c|c|c|c|c|c|}
\hline \multirow{2}{*}{ Results } & \multicolumn{7}{|c|}{ Mode number } \\
\cline { 2 - 7 } & 1 & 2 & 3 & 4 & 5 & 6 \\
\hline Leissa [1] & 9.096 & 10.37 & - & - & - & - \\
\hline Zhou [8] & 9.0719 & 9.1294 & 10.366 & 14.726 & 22.530 & 33.455 \\
\hline Present & 9.0257 & 9.0868 & 10.3267 & 14.6805 & 22.5682 & 33.4769 \\
\hline
\end{tabular}

Table 3. Comparison of the non-dimensional natural frequency parameter with Leissa [1] and Zhou [8] for free outer and free inner boundary $\left(v=1 / 3, r_{1} / r_{2}=0.4\right)$

\begin{tabular}{|c|c|c|c|c|c|c|}
\hline \multirow{2}{*}{ Results } & \multicolumn{7}{|c|}{ Mode number } \\
\cline { 2 - 7 } & 1 & 2 & 3 & 4 & 5 & 6 \\
\hline Leissa [1] & - & 4.567 & - & - & - & - \\
\hline Zhou [8] & 4.5325 & 8.5510 & 11.765 & 17.043 & 21.262 & 31.356 \\
\hline Present & 4.5197 & 8.5070 & 11.7368 & 16.9765 & 21.233 & 31.2565 \\
\hline
\end{tabular}

Table 4. Comparison of the non-dimensional natural frequency parameter with Leissa [1] and Zhou [8] for clamped outer and clamped inner boundary $\left(v=1 / 3, r_{1} / r_{2}=0.4\right)$

\begin{tabular}{|c|c|c|c|c|c|c|}
\hline \multirow{2}{*}{ Results } & \multicolumn{7}{|c|}{ Mode number } \\
\cline { 2 - 7 } & 1 & 2 & 3 & 4 & 5 & 6 \\
\hline Leissa [1] & 62.33 & 62.92 & 66.406 & - & - & - \\
\hline Zhou [8] & 61.872 & 62.966 & 66.672 & 73.630 & 84.594 & 99.904 \\
\hline Present & 62.0056 & 63.1121 & 66.7350 & 73.6148 & 84.5044 & 99.7988 \\
\hline
\end{tabular}


Table 5. Non-dimensional frequency parameter $\omega r_{2}^{2} \sqrt{\rho h / D}$ for the annular circular plate with clamped outer and free inner edge $(v=1 / 3)$

\begin{tabular}{|c|c|c|c|c|}
\hline \multirow{2}{*}{$n$} & \multicolumn{4}{|c|}{$r_{1} / r_{2}$} \\
\cline { 2 - 5 } & 0.2 & 0.4 & 0.6 & 0.8 \\
\hline 0 & 10.2922 & 12.871 & 25.3966 & 92.3617 \\
\hline 1 & 20.4306 & 18.497 & 28.3519 & 94.2334 \\
\hline 2 & 33.6865 & 29.001 & 36.2745 & 98.3097 \\
\hline 3 & 50.4963 & 44.70 & 47.9049 & 105.6264 \\
\hline 4 & 69.6342 & 62.982 & 62.8458 & 115.7173 \\
\hline 5 & 91.0597 & 83.751 & 79.4797 & 128.4994 \\
\hline
\end{tabular}

Table 6. Non-dimensional frequency parameter $\omega r_{2}^{2} \sqrt{\rho h / D}$ for the annular circular plate with free outer and clamped inner edge $(v=1 / 3)$

\begin{tabular}{|c|c|c|c|c|}
\hline \multirow{2}{*}{$n$} & \multicolumn{4}{|c|}{$r_{1} / r_{2}$} \\
\cline { 2 - 5 } & 0.2 & 0.4 & 0.6 & 0.8 \\
\hline 0 & 4.795 & 9.0257 & 20.5213 & 84.5418 \\
\hline 1 & 5.190 & 9.0868 & 20.8923 & 85.1491 \\
\hline 2 & 6.322 & 10.3267 & 22.3356 & 87.0250 \\
\hline 3 & 12.367 & 14.6805 & 25.6329 & 90.3110 \\
\hline 4 & 21.502 & 22.5682 & 31.5306 & 95.2026 \\
\hline 5 & 32.438 & 33.4769 & 40.3467 & 101.941 \\
\hline
\end{tabular}

Table 7. Non-dimensional frequency parameter $\omega r_{2}^{2} \sqrt{\rho h / D}$ for the annular circular plate with clamped outer and clamped inner edge $(v=1 / 3)$

\begin{tabular}{|c|c|c|c|c|}
\hline \multirow{2}{*}{$n$} & \multicolumn{4}{|c|}{$r_{1} / r_{2}$} \\
\cline { 2 - 5 } & 0.2 & 0.4 & 0.6 & 0.8 \\
\hline 0 & 4.795 & 9.0257 & 141.4272 & 593.2696 \\
\hline 1 & 5.190 & 9.0868 & 144.8754 & 593.8935 \\
\hline 2 & 6.322 & 10.3267 & 149.467 & 595.8484 \\
\hline 3 & 12.367 & 14.6805 & 156.3015 & 599.0929 \\
\hline 4 & 21.502 & 22.5682 & 165.7894 & 603.7515 \\
\hline 5 & 32.438 & 33.4769 & 178.2596 & 609.866 \\
\hline
\end{tabular}

\section{Conclusions}

In this paper, numerical analysis for free vibration analysis of a thin annular solid plate is carried out using the finite element method for different boundary conditions at the inner and outer radius. It is found that those natural frequency results are quite close to those reported in previous works of literature. The novelty of this paper is the effect of the radii ratio on natural frequency is discussed and found that with increasing radii ratio, natural frequency increases and another novelty is by using shell element modeling as per Abaqus convention the dimensionless frequency parameter as found in the literature are completely validated.

\section{References}

[1] Leissa A. W. Vibration of Plates. Office of Technology Utilization, Washington, 1969.

[2] Kim C. S., Dickinson S. M. On the free, transverse vibration of annular and circular, thin, sectorial plates subject to certain complicating effects. Journal of Sound and Vibration, Vol. 134, Issue 3, 1989, p. 407-421.

[3] Rajalingham C., Bhat R. B., Xistris G. D. Vibration of rectangular plates using plate characteristic functions as shape functions in the Rayleigh-Ritz method. Journal of Sound and Vibration, Vol. 193, Issue 2, 1996, p. 497-509. 
[4] Liew K. M., Yang B. Three-dimensional elasticity solutions for free vibrations of circular plates: a polynomials-Ritz analysis. Computer Methods in Applied Mechanics and Engineering, Vol. 175, Issues 1-2, 1999, p. 189-201.

[5] Zhou D., Au F. T. K., Cheung Y. K., Lo S. H. Three-dimensional vibration analysis of circular and annular plates via the Chebyshev-Ritz method. International Journal of Solids and Structures, Vol. 40, Issue 12, 2003, p. 3089-3105.

[6] Lim C. W., Li Z. R., Xiang Y., Wei G. W., Wang C. M. On the missing modes when using the exact frequency relationship between Kirchhoff and Mindlin plates. Advances in Vibration Engineering, Vol. 4, Issue 3, 2005, p. 221-248.

[7] Zhou Z. H., Wong K. W., Xu X. S., Leung A. Y. T. Natural vibration of circular and annular thin plates by Hamiltonian approach. Journal of Sound and Vibration, Vol. 330, Issue 5, 2011, p. 1005-1017.

[8] Kumar S., Vinayak Ranjan, Jana P. Free vibration analysis of thin functionally graded rectangular plates using the dynamic stiffness method. Composite Structures, Vol. 197, 2018, p. 39-53.

[9] Pratap Singh P., Azam M. S., Vinayak Ranjan Vibration analysis of a thin functionally graded plate having an out of plane material inhomogeneity resting on Winkler-Pasternak foundation under different combinations of boundary conditions. Proceedings of the Institution of Mechanical Engineers, Part C: Journal of Mechanical Engineering Science, 2018. 